\title{
A realidade do viver com esquizofrenia
}

\author{
The reality of living with schizophrenia \\ La realidad del vivir con esquizofrenia
}

\section{Renata Marques Oliveira', Priscila Cristina Bim Rodrigues Facina", Antônio Carlos Siqueira Júnior'II \\ ' Universidade de São Paulo, Escola de Enfermagem de Ribeirão Preto, Programa de Pós-Graduação em Enfermagem Psiquiátrica. (Mestranda) Ribeirão Preto-SP, Brasil. "Serviço Social da Construção Civil do Estado de São Paulo. Ribeirão Preto-SP, Brasil. "I' Faculdade de Medicina de Marília, Curso de Graduação em Enfermagem. Marília-SP, Brasil.}

\author{
Submissão: 10-01-2010 Aprovação: 30-05-2012
}

\section{RESUMO}

Objetivou-se entender a realidade do viver com esquizofrenia a partir do relato de quem a vivencia. Foram realizadas entrevistas com dez portadores de esquizofrenia internados em hospital geral, diagnosticados com o transtorno há, no mínimo, cinco anos. Para a análise do conteúdo das entrevistas foi utilizada a análise temática. Foi identificada a categoria "Convivendo com a esquizofrenia" e seis temas que abordam o conhecimento da doença, os sintomas, a difícil convivência, o estigma, a família e a religião. Esta pesquisa pode permitir a ampliação do olhar para os portadores de esquizofrenia, uma vez que o conhecimento sobre a doença e suas implicações ocorreram a partir da perspectiva de quem vivencia cotidianamente este sofrimento.

Descritores: Esquizofrenia; Qualidade de vida; Formação de conceito; Enfermagem psiquiátrica; Pesquisa qualitativa.

\section{ABSTRACT}

The study aimed to understand the reality of living with schizophrenia from the account of people who live with it. Interviews were conducted with ten patients with schizophrenia hospitalized in a general hospital, diagnosed with the disorder for at least five years. The thematic analysis was used for the content analysis. As results, it was identified the category "Living with schizophrenia" and six themes, which concern: the knowledge of the disease, the symptoms, the hardship of living with the illness, the stigma, the family and the religion. In conclusion, this work can allows broader look at people with schizophrenia, since the knowledge about the disease and its implications occurred from the perspective of who live with such suffering on a daily basis.

Key words: Schizophrenia; Quality of life; Concept formation; Psychiatric nursing; Qualitative research.

\section{RESUMEN}

Objetivó-se ccomprender la realidad del vivir con esquizofrenia a partir del discurso de quien la vivencia. Como método, se han realizado entrevistas con diez pacientes con esquizofrenia admitidos en un hospital general, diagnosticados con la enfermedad durante al menos cinco años. Para el análisis de sus contenidos fue utilizado el Análisis Temático. Fue identificada, como resultado, la categoría "Conviviendo con la Esquizofrenia" y seis temas, que abordan: el conocimiento de la enfermedad, los síntomas, la difícil convivencia, el estigma, la familia y la religión. En conclusión, este trabajo permitió la ampliación de la mirada para los portadores de esquizofrenia, ya que lo conocimiento de la enfermedad y sus implicaciones ocurrirán desde la mirada de quien vivencia diariamente ese sufrimiento.

Palabras clave: Esquizofrenia; Calidad de vida; Formación de concepto; Enfermería psiquiátrica; Investigación cualitativa. 


\section{INTRODUÇÃO}

A esquizofrenia é conhecida como uma das doenças psiquiátricas mais graves e desafiadoras. É definida como uma síndrome clínica complexa que compreende manifestações psicopatológicas variadas de - pensamento, percepção, emoção, movimento e comportamento ${ }^{(1-3)}$.

Trata-se de uma doença bastante prevalente dentre as condições psiquiátricas. Atualmente, os pacientes com esquizofrenia são maioria nos leitos de hospitais psiquiátricos. No Brasil aparecem cerca de 75.000 novos casos desse transtorno por ano, o que representa 50 casos para cada 100.000 habitantes ${ }^{(3-4)}$.

É comum, porém pode ser considerada pejorativa, a denominação "esquizofrênico" para o indivíduo portador de esquizofrenia, uma vez que é rotulado perante toda a sociedade. Ao serem rotulados, esquece-se que, em cada pessoa, a doença repercute de uma forma diferente. A mudança na maneira de se referir aos portadores de esquizofrenia tem sido uma tentativa de fazê-los ser considerados pessoas com um problema ao invés de pessoas-problemas ${ }^{(5)}$.

Essa preocupação acerca da denominação do portador de esquizofrenia faz parte das mudanças que vêm ocorrendo nos conceitos de doença mental e assistência na área, pois o foco principal não reside mais apenas no aspecto biológico, mas também nos aspectos psicossociais. Por essa nova concepção, trabalha-se com a ideia de descoberta de sentido mesmo na condição de adoecimento, visto que as potencialidades do portador de esquizofrenia não podem mais se resumir à doença( ${ }^{(6-7)}$.

Esse processo de descoberta de sentido na esquizofrenia torna-se um processo extremamente difícil e doloroso, pois a convivência com o transtorno é acompanhada de intenso sofrimento e limitações. As limitações, de modo geral, decorrem da deterioração de vários processos mentais, fazendo com que o indivíduo apresente alguns sintomas característicos da esquizofrenia, conhecidos como sintomas positivos e sintomas negativos ${ }^{(3,8-9)}$.

Os sintomas positivos são aqueles em que ocorrem comportamentos adicionais nos momentos de crise psiquiátrica como delírios, alucinações, alterações na fala e no comportamento (catatonia, transtornos dos movimentos, entre outros). Acredita-se que a apresentação dos sintomas positivos, especialmente os delírios e as alucinações, tem relação íntima com as particularidades de cada indivíduo, com suas experiências de vida e com as relações estabelecidas com os fatos ao seu redor, podendo ser considerada uma forma de o indivíduo comunicar seus medos e impulsos ${ }^{(3,5,10)}$.

Os sintomas negativos, por sua vez, são aqueles em que ocorre perda da função, caracterizando-se por diminuição da atividade motora e psíquica, bem como das manifestações emocionais, exemplificados como afeto plano e anedonia. Esses sintomas podem ocorrer também devido a causas secundárias da doença como privação ambiental, quadros depressivos, ansiedade, além dos efeitos colaterais das drogas antipsicóticas ${ }^{(3,10)}$.

Uma das maiores dificuldades da esquizofrenia reside em sua cronicidade (sintomas negativos) e na recorrência dos sintomas agudos (sintomas positivos). A apresentação desses dois tipos de sintomas é responsável pelas consequências pessoais do convívio com a esquizofrenia que são refletidas na vida afetiva, social, familiar e financeira, com destruição de sonhos, desconsideração do portador como ser humano, sentimentos de menos valia e sentimento de não ser compreendido pelos familiares e amigos ${ }^{(8-9)}$.

Considerando a complexidade, a severidade, o intenso sofrimento e os inúmeros prejuízos que a esquizofrenia pode causar-nos diversos aspectos da vida de seus portadores e seguindo as ideias de transformação dos conceitos de doença mental e assistência psiquiátrica, é importante um novo olhar para os portadores deste transtorno, dando-lhes voz, acolhendo e valorizando seus sofrimentos neste processo de descoberta de novo sentido para a convivência com a esquizofrenia.

Neste estudo, objetivou-se entender a realidade do viver com esquizofrenia, bem como suas implicações para o acometido por ela, a partir do relato de quem a vivencia.

\section{PERCURSO METODOLÓGICO}

Este estudo foi submetido à avaliação do Comitê de Ética em Pesquisa da Famema, tendo obtido sua aprovação sob Protocolo de estudo $n^{\circ} 227 / 08$, de acordo com a resolução 196/96.

Para alcançar seus objetivos foi utilizada a pesquisa de campo de natureza exploratória, segundo a abordagem qualitativa. Por meio da metodologia qualitativa exploratória, o pesquisador consegue compreender a realidade vivida pelos sujeitos envolvidos, a partir do contato direto com quem a vivencia. Por trabalhar com o universo dos significados, este tipo de metodologia permite ao pesquisador não somente descrever aquilo que observa, mas também interpretar, buscar explicações, reflexões e percepções das diferentes facetas do problema estudado ${ }^{(11-12)}$.

Como estratégia para descrever a experiência de ser portador de esquizofrenia foram realizadas entrevistas com dez sujeitos diagnosticados com o transtorno e internados na enfermaria de psiquiatria do Hospital das Clínicas de Marília. A amostra foi obtida de modo intencional não probabilístico, seguindo o critério de saturação empírica, definido por Glaser e Strauss ${ }^{(13)}$. As entrevistas, realizadas no período de junho a dezembro de 2008, foram baseadas na seguinte questão norteadora: Qual o significado de ser um portador de esquizofrenia?

As entrevistas somente foram realizadas após esclarecimento e assinatura do Termo de Consentimento Livre Esclarecido pelo participante do estudo e pelo familiar responsável. Como critério de inclusão, foi considerado o diagnóstico de esquizofrenia realizado há, no mínimo, cinco anos e a ausência de delírios e alucinações proeminentes no momento da entrevista, o que ocorreu perto do momento da alta hospitalar. As falas foram gravadas, transcritas e submetidas à análise temática.

Para analisar o conteúdo das entrevistas, foi utilizada a análise temática que consiste em descobrir os núcleos de sentido que compõem uma comunicação, cuja presença ou frequência signifiquem alguma coisa para o objetivo analítico visado $^{(11)}$. Para a realização deste tipo de análise são sugeridas 
três etapas: pré-analise, exploração do material e tratamento dos resultados obtidos. Na análise dos dados, os sujeitos do estudo são apresentados seguindo a codificação por nome de flores, de forma a garantir o anonimato.

\section{RESULTADOS E DISCUSSÃO}

Participaram deste estudo dez portadores de esquizofrenia, seis do sexo feminino e quatro do sexo masculino. A faixa etária foi bastante variada, de 21 a 50 anos. Quanto ao estado civil, quatro eram divorciados, quatro casados e dois solteiros. No que diz respeito à escolaridade, apenas um era analfabeto, três tinham o ensino fundamental incompleto, um tinha o ensino fundamental completo, três tinham o segundo grau incompleto, um tinha o segundo grau completo e um tinha o ensino superior incompleto.

Cinco dos entrevistados eram católicos, quatro evangélicos e um espírita. Quanto às atividades desenvolvidas antes de se tornarem portadores de esquizofrenia, dois eram estudantes, um não realizava nenhuma atividade e os demais trabalhavam em diferentes serviços. Após o início da manifestação da doença, sete dos entrevistados passaram a não exercer qualquer atividade, dois tornam-se usuários do Centro de Atenção Psicossocial (CAPS) e apenas um continuou trabalhando.

A partir do processo de análise dos dados foi identificada a categoria Convivendo com a esquizofrenia e seis temas: 1) a dificuldade de se conviver com a esquizofrenia e os prejuízos na qualidade de vida, 2) o conhecimento sobre a doença, 3) a estigmatização do doente mental e o autoestigma, 4) a convivência com os sintomas da esquizofrenia, 5) a difícil convivência da família com a esquizofrenia e 6) as influências da religião na convivência com a doença.

A trajetória do portador de esquizofrenia é repleta de muito sofrimento, pois o convívio com a doença ocasiona mudanças significativas na vida do indivíduo. Deste modo, o início da manifestação da doença pode ser visto como um marco entre o que era considerado normal e o que passa a ser considerado doentio.

\section{A dificuldade de se conviver com a esquizofrenia e os pre-} juízos na qualidade de vida

A dificuldade de se conviver com a esquizofrenia ficou muito evidente nas falas dos entrevistados. Isto se deve ao prejuízo que ocorre na qualidade de vida, termo este de grande importância ao se falar em doença crônica. Qualidade de vida é entendida como tudo aquilo que é significante para o indivíduo, sendo um conceito amplo que agrega todos os aspectos da existência do ser humano e sua impressão a respeito de cada uma delas, considerando também os diferentes contextos culturais ${ }^{(1,14)}$. Orquídea relatou de forma abrangente a dificuldade de se conviver com a doença:

\section{[...] Mudou minha vida totalmente pra pior. (Orquídea)}

A OMS (Organização Mundial da Saúde) compreende qualidade de vida como a saúde física, a saúde mental, o grau de independência que o indivíduo consegue ter em relação aos demais, as relações sociais e os mais diversos tipos de crenças, podendo-se considerar ainda o trabalho e as relações familiares. Os entrevistados relataram o comprometimento da qualidade de vida em alguns desses aspectos definidos pela OMS.

Meu pai achou melhor eu dar ele [filho] pra essa senhora. [...] Eu não ia conseguir cuidar dele porque eu só tava ruim. É verdade, eu tava ruim. (Margarida)

Eu estudava nutrição [...] peguei muita $D P$, minhas notas foram ruins. Numa prova de fisiologia eu acabei escrevendo várias palavras sem nexo. Ao invés de responder às perguntas, eu respondi outros tipos de assuntos. (Rosa)

Não tem disposição [para trabalhar]. Sempre gostei de trabalhar, de estudar, de sair à noite e eu não posso mais. Não tem como trabalhar, não tem disposição, não consegue se concentrar, tudo cansa rápido! Você pega uma coisa pra fazer e às vezes não conclui por inteiro, desanima [...] Eu tinha o meu dinheiro, hoje eu já não tenho, eu tinha responsabilidade, hoje eu já não tenho. (Orquídea)

Orquídea relatou a importância que a atividade de trabaIhar tinha em sua vida e a dificuldade de mantê-la a partir da convivência com a esquizofrenia. No caso da doença mental, trabalhar torna-se mais complicado, uma vez que são vários os fatores que prejudicam a sua concretização como baixa autoestima, dificuldade de lidar com situações frustrantes, medo de errar, dificuldade de viver de maneira independente e a ansiedade $^{(15)}$.

Em uma revisão da literatura científica, os autores apresentam dois estudos realizados sobre qualidade de vida e trabaIho na esquizofrenia. Um dos estudos mostra que os portadores de esquizofrenia que possuíam algum tipo de trabalho e consequentemente uma fonte de renda, mostraram-se com melhor qualidade de vida, comparados com aqueles que não trabalhavam. Já o segundo estudo mostra uma relação inversa ao considerar que o trabalho para estes indivíduos pode ser prejudicial, uma vez que pode ser exigente e estressante, fazendo com que os indivíduos tenham uma piora na qualidade de vida pelas restrições dos recursos pessoais de enfrentamento ${ }^{(1)}$, como observado abaixo:

[...] onde eu trabalhava não era bom pra mim por causa da patroa, né! Ela era muito exigente. (Violeta)

Trabalhar no meu caso não dá por causa do estresse. Se eu ficar em situação de estresse, de nervosismo ou de desentendimento, dá alucinação e ambiente de trabalho não é calmo. Eu já trabalhei e sei como é. (Orquídea)

A percepção dos prejuízos pelos indivíduos portadores de esquizofrenia varia de acordo com o tempo de diagnóstico da doença. Aqueles indivíduos com menor tempo de diagnóstico os vê de forma mais intensa, pois estão mais próximos do que era considerado padrão de normalidade por eles próprios, enquanto que aqueles que possuem maior tempo de diagnóstico 
já estão adaptados à nova condição, tendo criado, a partir da doença, um novo padrão de normalidade. Outra explicação dada pelo autor seria que a melhor adaptação pode ser decorrente do maior tempo de tratamento, fazendo com que o indivíduo apresente um quadro estável ${ }^{(16)}$.

Frente às inúmeras dificuldades ocorridas na esquizofrenia, é fundamental valorizar as atividades que o indivíduo ainda consegue realizar, sendo uma delas o autocuidado. $\mathrm{O}$ autocuidado pode ser entendido como o estímulo à preservação da capacidade de fazer parte do gerenciamento do seu tratamento, das relações sociais e familiares estabelecidas, bem como ter algum grau de controle e autonomia no ambiente em que vive; enfim, ser capaz de cuidar de si mesmo nos diferentes aspectos de sua vida. O importante é fazê-los se sentir ativos na construção de suas próprias histórias ${ }^{(15)}$.

\section{Conhecimento sobre a doença}

O significado que os portadores de esquizofrenia atribuem à doença é fortemente influenciado por fatores culturais, relacionamento familiar e tipo de tratamento recebido. Uma concepção cultural bastante frequente sobre a esquizofrenia é sua explicação como um "problema na cabeça", o que pode ser entendido como uma forma de conviver melhor com a dura realidade, uma vez que resistem em utilizar a palavra esquizofrenia, adotando termos mais abrangentes ao se referirem à doença ${ }^{(17)}$.

Deve ser alguma coisa da cabeça, né, mas certeza, certeza, eu não sei. (Girassol)

\section{[...] Indaguei que poderia ser um desequilíbrio químico do} cérebro. (Rosa)

Este modo de se referir à doença e à sua realidade não se explica somente pelo desconhecimento ou incerteza sobre ela. Na verdade, esses pacientes mostram uma apropriação do conhecimento biológico, ao atribuir a uma determinada parte do corpo a responsabilização da esquizofrenia ${ }^{(17)}$. Essa priorização do conhecimento biológico é decorrente do fato de que a assistência à saúde mental é ainda muito voltada para as causas orgânicas, sendo menos abordados os aspectos psicológicos e sociais ${ }^{(18)}$.

Considerando que, apesar da convivência diária com a esquizofrenia, o indivíduo muitas vezes não tem compreensão do seu real significado, deve-se considerar a importância de se conhecer a doença.

É importante que a equipe de saúde não esteja presente somente nos cuidados durante a fase aguda, mas que também atente à necessidade de ajudar o paciente e sua família a conhecer melhor a doença, já que, apenas a partir de sua compreensão, é que pode haver uma melhoria na qualidade de vida, tanto do portador de esquizofrenia como na de seus familiares $^{(19)}$.

Quando o paciente e a família passam a conhecer a doença, conseguem identificar antes da equipe as situações de risco para recaídas e os sintomas precedentes, bem como os efeitos colaterais das medicações. Nesse caso, é possível que a equipe de saúde intervenha de forma precoce no processo de recaída, numa tentativa de estabilizar o quadro do paciente ${ }^{(20)}$. Isto pode ser evidenciado na fala a seguir:

Eu tenho sensibilidade, hoje eu sei, se eu tiver aqui conversando com vocês eu posso sentir. Se eu for ter alucinação eu sei, eu já busco ajuda antes. (Orquídea)

Uma maneira de melhorar o entendimento do paciente e da família sobre a doença é por meio da psicoeducação, que pode ser entendida como o fornecimento de informações sobre os sintomas, a etiologia, o tratamento e o modo de viver melhor sendo um portador de doença mental ${ }^{(21)}$.

\section{A estigmatização do doente mental e o autoestigma}

O estigma é algo que se faz presente no cotidiano do portador de esquizofrenia. Quando ocorre a estigmatização, o indivíduo passa a ser visto apenas com o enfoque na doença e nas suas consequências, tendo suas particularidades pessoais desconsideradas ${ }^{(22)}$. Desse modo, aquilo que ainda é preservado no indivíduo torna-se insignificante e os defeitos se sobressaem ao que ainda poderia ser considerado normal.

As consequências da estigmatização para o doente são a perda da autoestima, a perda da dignidade, os sentimentos de desesperança, o afastamento das relações sociais, a perda da cidadania e de seus direitos, diminuindo as possibilidades de ressocialização, uma vez que, na visão da sociedade, estes indivíduos fogem das normas sociais ${ }^{(19,23)}$.

Como fator causal da estigmatização, pode-se considerar a falta de conhecimento acerca da doença, o que é responsável pelas idéias preconceituosas, assim como o temor daquilo que não se conhece e de suas consequências ${ }^{(23)}$.

É reconhecido que o louco, ao mostrar a face sadia, é insuportável, pois se aproxima do normal. Parece existir a necessidade de se criar uma barreira entre o "ser louco" e o "ser normal", uma vez que, quando o lado ainda preservado do "louco" é reconhecido, a proximidade com a loucura fica mais evidente, fazendo com que se estigmatize o doente mental ${ }^{(23,24)}$.

A necessidade de se criar esta barreira pode ser explicada ao pensar que, apesar de ser difícil compreender o conteúdo das falas dos portadores de esquizofrenia, é muito raro alguém ouvir e não se abalar ou dar significado ao que é dito. $\mathrm{O}$ que os portadores de esquizofrenia dizem provavelmente é o que a nossa sociedade considerada "normal" não tem coragem de dizer, do mesmo modo como suas atitudes e comportamentos concretizam aquilo que muitos pensam, mas temem realizar ${ }^{(25)}$. Ao perceber esta semelhança e a fragilidade do simples fato de ser humano, o estigma passa a ser visto como poderoso meio de defesa. Os entrevistados relataram suas percepções sobre a aceitação/preconceitos por parte das pessoas que os cercam:

Eu não gosto quando os vizinhos de casa me chamam de louca. Todos os meninos da rua me chamam de louca: lá vem a louca! Falei: louca é quem come merda e rasga dinheiro. Dá um dinheiro aí pra ver se eu rasgo. Eu fico 
nervosa! [...] Não posso falar disso que eu fico com vontade de chorar. (Margarida)

Acho que mudam [as pessoas]. Mudam porque só o nome já diz: esquizofrenia! Só o nome já assusta! [...] Eu acredito que é assim. (Girassol)

O diferente assusta, afastou todo mundo depois que eu fiquei doente [...] permaneço com o mesmo círculo de amizades que eu já tinha. Fora os que já se afastaram porque eu sou assim. (Orquídea)

Ao conviver constantemente com essas situações de estigmatização, tanto pela sociedade em geral, como muitas vezes pela própria equipe de saúde, os indivíduos acabam internalizando essas situações, de forma a se autoestigmatizarem, o que é mais difícil de ser superado ${ }^{(15)}$.

Me sinto diferente, tudo em mim é diferente [...] Só me sinto igual a quem tem o que eu tenho [...] (Orquídea)

As consequências do autoestigma envolvem sentimentos de incapacidade, menos valia, incompreensão, culpa e falta de esperança, o que influencia o planejamento de um futuro melhor para o indivíduo, uma vez que o sujeito se sente desqualificado e com baixa autoestima ${ }^{(22)}$.

A fala de Orquídea, no exemplo acima, exemplifica bem a situação do autoestigma, pois a convivência constante dos portadores de esquizofrenia com o estigma provindo da sociedade como um todo faz com que eles internalizem as concepções pejorativas, o que os leva a se verem de forma diferente, não se permitindo conviver bem em sociedade.

\section{A convivência com os sintomas da esquizofrenia}

Os sintomas provocados pela esquizofrenia são os mais severos e temidos dentre as enfermidades psiquiátricas, pois significam a perda do controle da vida e das emoções e as pessoas se veem frente a uma inundação de pensamentos desconexos e de percepções até então desconhecidas ${ }^{(26)}$.

O indivíduo perde a noção do que é ou não é real, passando a viver num "mundo substituto" repleto de percepções visuais, auditivas e sensitivas que somente ele vê, somente ele ouve e somente ele sente, ou seja, os sentimentos ocasionados pela nova realidade são vividos de forma solitária ${ }^{(25)}$.

No decorrer das entrevistas, foi possível perceber como o tratamento medicamentoso e as orientações dadas pelos profissionais foram importantes para alguns pacientes se convencerem de que os sintomas não são reais. Orquídea e Girassol, em suas falas, demonstram que, apesar de reconhecerem o quão difícil é ter alucinações, em um segundo momento explicam como foi o processo de aceitação no decorrer dos anos:

[...] vozes de comando: se mata! Ou pra matar alguém da família [...] Pede pra cortar o pescoço, pede pra pegar álcool, pede pra por o cachorro na casa, pra cortar a mangueira do botijão, tudo o que é de ruim eu escuto [...] se não tiver ninguém por perto na hora pode cometer [suicídio], mesmo sabendo que é só pra mim, que ninguém tá vendo. (Orquídea)

Eu tentava convencer todo mundo de que era real e pra mim é. Eu tô vendo, pra mim é! Depois que os anos foram passando, os remédios foram mudando, eu passei a entender. Agora até no surto eu consigo entender que não é real. (Orquídea)

Parecia que uma pessoa ficava falando no meu ouvido [...] que nem quando uma pessoa tá conversando [...] Quando eu tava no hospital eu expliquei das vozes pro médico, aí os outros pacientes que escutaram começaram a dar risa$d a$, acharam que eu tava falando besteira. (Girassol)

Não acredito mais, não, isso aí veio da própria cabeça, né! [...] Quando eu comecei o tratamento e parou [as alucinações] eu pensei: o tratamento resolveu, o remédio resolveu o problema. Aí eu entendi que não era verdade. (Girassol)

Já Rosa, em sua primeira fala, descreve as alucinações auditivas demonstrando ter certeza de sua real existência, porém, no segundo momento da entrevista, mostra-se indecisa quanto à questão. Isso equivale a uma das etapas do processo de aceitação, sendo fundamental que os profissionais a reconheçam, uma vez que cabe a eles instigar a dúvida nos seus pacientes:

Pelo menos umas 50 vozes [...] cada uma tem um nome. Um se chama Alvin, ele é homossexual [...] fica contando histórias. O outro é Daiá-Conxú, tradição chinesa, ele gosta de conversar. [...] Respondo mentalmente, às vezes é preciso da boca mesmo. O duro é que minha mãe acha que eu tô falando sozinha, é estranho! [...]. (Rosa)

[...] Às vezes eu acho que são reais, às vezes eu acho que eu tô ficando louca de novo, então é uma indecisão. (Rosa)

Nas falas de Violeta, fica evidente que, em nenhum momento, ela aceitou os sintomas da doença como não sendo reais, o que tornou sua realidade mais sofrida, levando-a a atos de desespero como a retirada de todos os fios de cabelo da cabeça.

Eu ouço, tá tudo em volta. [...] É voz de gente viva mesmo com quem eu converso [...] São vozes inimigas [...] É a Geraldina e o velho, conversam à noite [...] Elas falam alto, né! [...] falam coisa ruim, coisas mandadas, né. (Violeta)

O que a gente vê é a realidade, é verdade, né! [...] eu chamo ela [irmã] pra ir na delegacia pra confirmar que a gente tem ladrões perto de casa, mas ela não acredita e eu acabo arrancando [o cabelo]. (Violeta)

Pelas falas apresentadas, são percebidas diferentes atitudes dos portadores de esquizofrenia frente à experiência dos sintomas psicóticos. Alguns entrevistados aceitam os sintomas como não sendo reais, alguns já se permitem a dúvida, enquanto outros os percebem como reais. A partir disso, vale ressaltar a 
importância dos profissionais estarem atentos para essas questões, respeitando o momento de aceitação de cada um, mas sempre os estimulando a distinguir o que é ou não real.

\section{A difícil convivência da família com a esquizofrenia}

Durante a convivência com a esquizofrenia, a família também participa do sofrimento. Orquídea ressaltou o apoio recebido de seus familiares e também fala da incompreensão de sua doença por pessoas fora de seu convívio familiar. A família deve ser vista por seus membros como um porto seguro, em que se encontra apoio e compreensão ${ }^{(27)}$.

[...] sempre tive apoio e eles compreendem o que eu tenho, todo mundo da minha casa. Amigos, parentes e pessoas que não moram comigo não entendem [...]. (Orquídea)

A família é importante por ser considerada uma continuidade do paciente. $\mathrm{O}$ modo de pensar e agir dos familiares afeta diretamente o ente adoecido ${ }^{(28,29)}$. No entanto, não é sempre que os familiares estão dispostos a se envolver com os problemas do ente adoecido e com seu tratamento. A não aceitação por parte da família é prejudicial para o portador de doença mental, visto que ele pode se sentir desamparado. A dificuldade de aceitação do doente no convívio familiar ficou bastante evidente nos discursos.

[...] até hoje não me aceitam [irmãos] na casa deles [...] não deixam eu ficar na casa deles, mandam eu ir embora pra minha casa. (Dama da Noite)

Eles [familiares] não ligam muito pra mim, não. [...] Cada um vive a vida deles, de vez em quando perguntam como que tá. (Copo de Leite)

O convívio com o portador de esquizofrenia é um processo complicado, principalmente para os familiares que convivem diariamente com ele. Com o início da doença e as alterações comportamentais do indivíduo com esquizofrenia, a família passa por diversas mudanças em seu dia a dia, uma vez que ele requer muita atenção e a família acaba cedendo por ter receio de que este, ao ser contrariado, mostre-se agressivo. Além disso, a prolixidade, muitas vezes sem sentido para quem escuta, torna-se exaustiva à medida que ocorre ${ }^{(29)}$.

Com o início da doença e os episódios de crise, as famílias sofrem um impacto muito grande, sendo que as estruturas antes existentes podem não ser capazes de ajudá-las a suportar o momento ${ }^{(29)}$. Então, a convivência constante com a doença mental gera uma sobrecarga emocional bastante intensa para a família ${ }^{(7,29)}$. No decorrer das entrevistas, houve a contribuição de um familiar que acompanhava um dos entrevistados:

Mudou horrivelmente, terrivelmente, que palavra mais eu posso dizer?! Pra mim não foi legal [...] Carga pesada! Eu, na minha vida, isso aí não é um probleminha, isso aí virou uma jamanta! Enorme! Matou eu, moça! (mãe da Rosa)
Devido à complexidade da doença e do sofrimento durante sua descoberta, alguns familiares podem ter atitudes de não aceitação e negação frente aos primeiros sinais da doença ${ }^{(30)}$ como uma forma de se proteger, como visto no relato abaixo:

[...] Gritei: mãe, vem cá, um vulto! Minha mãe não me deu muita atenção, fez uma cara como se eu estivesse mentindo: não foi nada, você não viu nada... (Cravo)

Essa atitude por parte da família é prejudicial para o doente mental, uma vez que o fato de negar a doença não faz com que ela deixe de existir e afasta, ainda mais, o doente do convívio familiar, fazendo com que passe a se sentir sozinho frente a uma situação desconhecida e aterrorizante.

\section{As influências da religião na convivência com a doença}

A religiosidade é um aspecto bastante importante na vida das pessoas, interferindo na saúde e nos transtornos mentais $^{(31)}$. Ela pode ser entendida como recurso de ajuda para a difícil convivência com a doença mental, auxiliando em sua compreensão, uma vez que atribuem a Deus a sua responsabilidade. Este comportamento permite suportar melhor o convívio com a esquizofrenia e suas consequências ${ }^{(17)}$.

Por ser uma doença crônica sem possibilidade de cura, seus portadores encontram na religião uma fonte de conforto e esperança, um "pronto-socorro espiritual" (31), onde se acredita na possibilidade de haver cura divina. No caso dos evangélicos, a religião é também vista como fonte de ajuda para o portador de doença mental devido às relações sociais estabelecidas com a comunidade religiosa, o que pode ser comprovado com o menor tempo de internação que seus fiéis costumam apresentar ${ }^{(31)}$.

A proximidade, de forma intensa, do portador de doença mental com as questões religiosas pode representar, porém, uma possibilidade de recaída ${ }^{(17)}$. Um aspecto negativo das igrejas mais conservadoras é a não aceitação do tratamento medicamentoso como recurso para controle da sintomatologia, julgando-se aptas a apoiar os indivíduos portadores de doença mental com base apenas no diálogo e na oração ${ }^{(31)}$.

No começo, acho que em quase todos os casos, as pessoas pensam que é espiritual. É o que eu pensava também, pensava que era coisa de outro mundo, que era espiritual, igreja assim ia resolver o meu caso e não remédio e médico [...] É muita gente falando: joga os remédios fora, você não precisa disso, vai numa igreja... (Orquídea)

[...] falam que é pra eu ir na igreja que tudo vai acabar e que é coisa da minha mente. Eles curam, né! [...] Agora eu sou espírita [...] a gente tem o dom, né, fia [...] eu sou médium, né [...]. (Violeta)

Com as falas dos entrevistados, reconhece-se que a religiosidade realmente é bastante importante na vida dos indivíduos portadores de doença mental, mas que muitas vezes eles são influenciados de maneira negativa por ela, agravando o curso da doença. Cabe aos profissionais da saúde mental identificar que tipo de contribuição a religião tem na vida 
desses indivíduos e, dependendo das influências exercidas, alertá-los para o fato.

\section{CONCLUSÕES}

A partir do resultado apresentado neste estudo, é possível compreender como é importante escutar as pessoas que vivenciam a esquizofrenia diariamente em todos os seus aspectos. As falas dos entrevistados foram surpreendentes, pois deixaram implícito o significado de ser um portador de doença mental. O momento da entrevista foi também de grande importância para a valorização destes indivíduos, uma vez que tiveram oportunidade de ter seus sofrimentos acolhidos, escutados e valorizados, exercitando, mesmo que singela e temporariamente, seu direito de cidadania.

Os entrevistados puderam expressar, nos relatos, o sofrimento vivenciado a partir do convívio com a esquizofrenia e os prejuízos na qualidade de vida, de forma especial nos relacionamentos, nas atividades diárias, no trabalho e no estudo. Os próprios entrevistados mostraram ter consciência da influência direta da esquizofrenia nesses aspectos da vida.

Os pacientes entrevistados ainda mostraram conhecimento sobre a doença, sendo que muitos atribuíram sua ocorrência a fatores orgânicos, chegando a e evitar o uso da palavra "esquizofrenia" para se referir à doença, preferindo a utilização de termos mais abrangentes e menos impactantes. No entanto, apesar de evitarem o uso do nome da doença, mostraram como a convivência com ela os ajudou a conhecê-la em seus diferentes aspectos, inclusive ajudando-os na prevenção de crises.

Uma questão muito delicada abordada nos relatos diz respeito ao estigma que os portadores de esquizofrenia percebem das pessoas que vivem ao redor e ao autoestigma, mais limitante e causador de maior sofrimento do que aquele advindo da sociedade.

Ao falarem da difícil convivência com a doença, ficou muito evidente a importância da família nesse processo. Não houve, no entanto, homogeneidade nos relatos, pois algumas pessoas verbalizaram sentir-se apoiadas, enquanto outras não. Isso permite afirmar que cada família reage de um modo diferente frente à convivência com a doença mental.

A religião também foi lembrada como auxílio na convivência com a esquizofrenia, tendo como aspecto negativo a influência de algumas pessoas que incentivam o doente a abandonar os remédios e procurar apenas a cura divina.

Espera-se que este estudo ajude os estudantes e os profissionais da saúde a conhecerem, a partir do relato dos portadores de esquizofrenia, o real sofrimento ocasionado por esta difícil convivência e que, a partir deste conhecimento, reflitam sobre sua prática cotidiana, uma vez que, independente da área em que o profissional da saúde escolha atuar, sempre haverá oportunidade de acolher um portador de doença mental com dignidade e respeito à sua cidadania. Espera-se também que este estudo seja motivador para a realização de muitos outros, pois a pesquisa sempre prossegue, nunca estará concluída, havendo sempre novas verdades a serem desocultadas ${ }^{(32)}$.

\section{AGRADECIMENTOS}

Agradecemos à equipe da Enfermaria De Psiquiatria do Hospital das Clínicas de Marília pelo apoio durante a coleta dos dados; e à Adriana Marques de Oliveira pela revisão crítica do trabalho.

\section{REFERÊNCIAS}

1. Souza LA, Coutinho ESF. Fatores associados à qualidade de vida de pacientes com esquizofrenia. Rev Bras Psiquiatr 2006;28(1):50-8.

2. Sadock BJ, Sadock VA. Kaplan \& Sadock compêndio de psiquiatria: ciência do comportamento e psiquiatria clínica. 9. ed. Porto Alegre: Artmed; 2007.

3. Organização Mundial da Saúde. Classificação Estatística Internacional de Doenças e Problemas relacionados à Saúde - CID-10. 8.ed. São Paulo: Edusp; 2000.

4. Chaves AC. Diferenças entre os sexos na esquizofrenia. Rev Bras Psiquiatr 2000;22 Suppl 1: 21-22.

5. Holmes DS. Transtornos esquizofrênicos: sintomas e questões. In: Holmes DS. Psicologia dos transtornos mentais. 2. ed. Porto Alegre: Artmed; 2001. p. 235-58.

6. Travelbee J. Intervención em enfermería psiquiatria: el processo de la relación de persona a persona. Washington: OPAS/OMS; 1982.

7. Cavalheri SC. Transformações do modelo assistencial em saúde mental e seu impacto na família. Rev Bras Enferm 2010;63(1):51-7.

8. Noiseux S, Ricard N. Recovery as perceived by people with schizophrenia, family members and heatlh professionals: a grounded theory. Int J Nurs Stud 2008;45:1148-62.

9. Mauritz M, Meijel BV. Loss and grief in patients with schizophrenia: on living in another world. Arch Psychiatr Nurs 2009;23(3):251-60.

10. Gabbard GO. Esquizofrenia. In: Gabbard GO. Psiquiatria psicodinâmica. 2. ed. Porto Alegre: Artes Médicas; 1998. p. 133-54.

11. Minayo MCS, organizador. Pesquisa social: teoria, método e criatividade. 22. ed. Petrópolis: Vozes; 2007.

12. Trivinõs ANS. Introdução à pesquisa em ciências sociais: a pesquisa qualitativa em educação. São Paulo: Atlas; 1992.

13. Glaser BG, Strauss AL. The Discovery of grounded theory: strategies for qualitative research. New York: Aldine De Gruyter; 2009.

14. Teixeira MB. Qualidade de vida de familiares do doente esquizofrênico. Rev Paul Enferm 2006;25(2):82-9.

15. Hirdes A. Autonomia e cidadania na reabilitação psicossocial: uma reflexão. Ciênc Saúde Coletiva 2009;14(1):165-71. 
16. Cardoso CS, Caiaffa WT, Bandeira M, Siqueira AL, Silva JT, Fonseca JOP. Depressão na esquizofrenia: prevalência e relação com a qualidade de vida. Cad Saúde Pública 2007;23(9): 2035-48.

17. Villares CC, Redko CP, Mari JJ. Concepções de doença por familiares de pacientes com diagnóstico de esquizofrenia. Rev Bras Psiquiatr 1999;21(1):36-47.

18. Pereira MAO. Representações sociais de pacientes psiquiátricos sobre a loucura, a internação e o sofrer psíquico: a triste passagem e a triste paisagem. Ribeirão Preto. Tese [Doutorado em Enfermagem]- Escola de Enfermagem de Ribeirão Preto, Universidade de São Paulo;1997.

19. Spadini LS, Souza MCBM. A doença mental sob o olhar de pacientes e familiares. Rev Esc Enferm USP 2006;40(1):123-7.

20. Durão AMS, Souza MCBM, Miasso Al. Cotidiano de portadores de esquizofrenia após uso de clozapina e acompanhamento grupal. Rev Esc Enferm USP 2007;41(2):251-7.

21. Fresán A, Apiquian R, Ulloa RE, Loyzaga C, García Anaya M, Gutiérrez D. Ambiente familiar y psicoeducación en el primer episodio de esquizofrenia: resultados preliminares. Salud Ment 2001;24(4):36-40.

22. Araújo TCBC, Moreira V, Cavalcante Jr FS. Sofrimento de Sávio: estigma de ser doente mental em Fortaleza. Fractal Rev Psicol 2008;20(1):119-28.

23. Graham N, Lindesay J, Katona C, Bertolote JM, Camus V, Vicent $C$, et al. Redução da estigmatização e da discriminação das pessoas idosas com transtornos mentais: uma declaração técnica de consenso. Rev Psiquiatr Clín (São Paulo) 2007;34(1):39-49.

24. Humerez DC. História de Hélia: referência existencial da esquizofrenia paranóide. Acta Paul Enferm 2000;13(1):55-65.

25. Diatkine R, Quartier-Frings F, Andreoli A. Psicose e mudança. São Paulo: Casa do Psicólogo; 1993.

26. Coelho VLD, Hollanda DM. Quando o usuário é autor: reflexões sobre depoimentos redigidos por pacientes com esquizofrenia. J Bras Psiquiatr 2002;51(6):341-52.

27. Teixeira MB. Qualidade de vida de familiares cuidadores de esquizofrênicos. Rev Bras Enferm 2005;58(2):171-5.

28. Durão AMS, Souza MCBM, Miasso AI. Grupo de acompanhamento de portadores de esquizofrenia em uso de clozapina e de seus familiares: percepção dos participantes. Rev Bras Enferm 2005;58(5):524-8.

29. Koga M, Furegato AR. Convivência com a pessoa esquizofrênica: sobrecarga familiar. Ciênc Cuid Saúde 2002; 1(1):75-9.

30. Babls SC, Zacar FMH. A família e as abordagens psicossociais na esquizofrenia Psicol Argum 2004;22(39):27-34

31. Dalgalarrondo P, Banzato CEM, Botega NJ. Frequência aumentada de esquizofrenia em pacientes evangélicos internados. J Bras Psiquiatr 2004;53(3):143-52.

32. Boemer MR. A condução de estudos segundo a metodologia de investigação fenomenológica. Rev Latinoam Enferm 1994;2(1):83-94. 